\title{
Secondary school students' engagement in learning Japanese as a second language
}

\author{
Yuko Asano-Cavanagh $(\mathrm{PhD})$ and Rob Cavanagh $(\mathrm{PhD})$ \\ Curtin University of Technology, Perth, Western Australia
}

Paper submitted to the 2009 Annual Conference of the Australian Association for Research in Education: Canberra.

\begin{abstract}
The learning of Asian languages is a significant feature of national and state education policies. For example, the multi-million dollar National Asian Languages and Studies in Schools Program which was designed to increase participation and engagement in learning Asian languages. While much of the impetus for this press is due to international trade and economic priorities, the curriculum area of languages other than English is also important for educative and cultural reasons. Of the four Asian languages typically taught in local schools (Indonesian, Japanese Korean and Mandarin), Japanese has the highest enrolment.
\end{abstract}

The research reported in this paper focussed on the engagement of Western Australian secondary school students in their classroom learning of Japanese. While the study of second language instruction and teaching is situated within the field of second language acquisition, it also applies conventional educational theory. For example, cognitive, meta-cognitive and socio-affective constructs. This similarity is reflected in the model of student engagement that informed instrumentation decisions in the investigation of local Japanese classroom learning. Engagement was conceptualised as a function of student capability for learning and the expectations placed on this learning. Capability was defined in terms of self-esteem, self-concept, resilience, selfregulation and self-efficacy. Expectations were defined as facets of learning for understanding expectations of explanation, interpretation, application and having perspective, empathy and selfknowledge.

A self-report instrument was administered to 278 Years Eight to Twelve students. The instrument comprised 50 statements about attributes of students and their learning. Students responded on a four-category response scale. The data were tested against the Rasch rating Scale Model. Data fitting the model shows a uni-dimensional trait was measured and the measure was invariant. Data-to-model fit was assessed by estimation of item difficulty thresholds, individual item fit statistics, the Person Separation Index and Principal Components Factor loadings of residuals. The difficulty students had in affirming individual statements and groups of statements were also estimated to indicate common and less common perceptions of Japanese classroom learning. The results showed a balance between student views of their capability for learning and the expectations of this learning. Engagement was characterised by resilience, self-regulation and self-efficacy. The students affirmed expectations of explanation, interpretation, application and having perspective, empathy and self-knowledge. The perspective and empathy items were more highly affirmed.

The empirical findings are discussed in consideration of second language instruction and learning theory. The paper concludes with some recommendations for instrument improvement and future studies. 
Address correspondence to:

Dr Yuko Asano-Cavanagh,

Department of Asian Languages,

Curtin University of Technology

GPO Box U1987

Western Australia 6845

Email: Y.Asano@,curtin.edu.au

Phone: +61892667689

Fax: +61 892662547

The research was conducted as part of an Australian Research Council funded Linkage Project between Curtin University of Technology and the Participation Directorate of the Western Australian Department of Education and Training. 


\section{Secondary school students' engagement in learning Japanese as a second language}

\section{Introduction}

This paper commences by examining the importance of learning a second language in Australia. Then, theories of language acquisition and methods of L2 learning and instruction are discussed. A model of student engagement in classroom learning is then proffered as a suitable theoretical model upon which to base an investigation of engagement in learning Japanese as a second language. The research questions are presented next, followed by an account of the methodology and results. Finally, the results are discussed in relation to theoretical issues in L2 learning.

\section{Background}

\section{Significance of studying languages other than English (LOTE)}

One of the eight key learning areas specified in the Australian National Goals for Schooling in the Twenty-First Century and endorsed by the Ministerial Council on Education, Employment, Training and Youth Affairs (MCEETYA, 1999) is LOTE Languages other than English. A significant factor in LOTE policy and practice in Australia has been national government support for Asian languages and Asian studies in all school systems. The rationale for this priority was economic with the intention of improving Australia's capacity and preparedness to interact with Asian economies (DEEWR, 2002). In recent times this is shown by the Australian Government committing funding of $\$ 62.4$ million over 2008/09 to 2010/11 for the National Asian Languages and Studies in Schools Program (NALSSP) (DEEWR, 2008). Prior to this national policy development, there were the beginnings of regional consciousness in the mid-1960s to mid-1970s, multi-cultural and Asia-literacy policies mid-1970s to late-1980s, and the Tsunami in the 1990s (Lo Bianco, 2000). The Tsunami period was a time of extensive interest and growth in learning the Japanese language. This was characterised by: "vast and rapid enrolment increases in Japanese language study - all levels, all states"; "Japanese becomes language of mass education; "Japanese taught at every university"; and Japanese emerging as a community language as well" (Lo Bianco, 2000, p. 16). The impetus for these cultural shifts can be explained by the development of the Japanese economy and the expansion of trade with Australia that commenced in the 1970s.

In Western Australia, of the four languages targeted for national support (Chinese [Mandarin], Indonesian, Japanese and Korean), Japanese has the highest enrolment (Curriculum Council, 2008). This is notwithstanding a recent upsurge in Chinese enrolments that has likely been stimulated by local reactions to the growth in the Chinese economy and the state's trade with China.

Another important reason for LOTE instruction being nationally prominent centres on students' cultural learning as well as complementing other areas of the curriculum. For example, the Queensland Department of Education, Training and the Arts (2006) states that "Learning a language other than English:

- introduces students to other languages as a means of accessing other peoples, ideas and ways of thinking;

- inspires interest in and respect for other cultures;

- intersects with a range of communication technologies; and 
- develops an array of transferable skills that support other areas of the curriculum" (p. 1).

As a result of Australia's international economic relationships and the importance of LOTE as a curriculum area, it is likely that the study of the Japanese language in local schools will continue to be a significant component of schooling as will be the study of Asian languages in general. Consequently, aspects of Japanese subject instruction and learning, the outcomes of studying Japanese, and in general, the engagement of students in Japanese subject classrooms are important areas of educational research.

\section{Theories of language acquisition}

Larsen-Freeman and Long (1991) grouped theories of second language (L2) acquisition into three types - nativist, environmentalist and interactionist. In very broad terms, the nativist view assumes: that learners have "... knowledge that does not appear to derive from experience" Hawkins, 2008, 476); that "language acquisition is largely the result of children's innate, biological endowment" (Stromswold, 2006, p. 341); and that "genetic mechanisms ....account for specific brain structures (Quartz, 1993, p. 224). The innate knowledge that enables language acquisition was termed Universal Grammar by Chomsky (1972) - universal language specific knowledge.

Environmentalist theories challenge the nativist view by holding that an organism's experiences shape its development. The environmentalist view is typified by behaviourist and neo- behaviourist learning theories. These underpin stimulus-response instructional strategies that largely rely on "... imitation and discrimination drills, reading aloud and contrastive analysis of L1 and L2 sound systems" (Jones, 1997, p. 103). This view is also consistent with connectionist models of language learning in which the connection of neural networks and indeed brain functioning are considered to require the input of stimuli (see Nakagama \& Tanaka, 2004).

Interactionist theories " ... invoke both innate and environmental factors to explain language acquisition" (Larsen-Freeman \& Long, 1991, p. 266). For example, "Social interactionists believe that children acquire the ability to express their intentions or meanings in language through a process of negotiation with their mothers or principal caregivers" (Matychuk, 2005, p. 304). Another interactionist perspective is functionalism. "The functionalist viewpoint in linguistics can take different forms. A caricature of functionalist thinking is the notion that the structure of language is optimised, or nearly so, for its function as a means of human communication" (Pierrehumbert, 2002, p. 459). From this perspective, functionalism is also about the pragmatic function of language communication.

This brief overview of language acquisition theories has revealed a complex and at times contradictory body of knowledge about learning and processes of learning. Pragmatically, if instructional methods are grounded in multiple models of learning then this theoretical diversity could well be reflected in the use of multiple ways of teaching second languages. The following section presents constructs, strategies and processes that exemplify how language acquisition theories in conjunction with more general pedagogical theories have been applied in the design and delivery of L2 learning. 


\section{L2 learning and instruction}

When reporting on a meta-analysis of the effectiveness of L2 instruction, Norris and Ortega (2000. p. 420) proposed three types of instructional options based on the focus required of the learner - "focus on meaning, forms, or an integration of both meaning and forms". First, focus on meaning "leads to incidental acquisition of the L2 system from exposure to rich input and meaningful use of the L2 (p. 420). Second, " focus on forms in isolation (FonFS instruction) assumes the target L2 forms can and need to be taught one by one in a sequence externally orchestrated according to linguistic complexity" (p. 420). Third "focus on forms integrated in meaning (FonF instruction) capitalises on brief reactive interventions ... [that] draw learners' attention to formal properties of a linguistic feature which appears to cause trouble on that occasion [and], is learnable" (p. 420). The meta-analysis revealed that "both FonF and FonFS instructional categories had large average effect sizes" (p. 482), but also found there were "no differences in effectiveness between FonF and FonFS instruction" (p. 482).

L2 instruction can be also classified as explicit or implicit depending on the degree of explanation and the attention given to the second language structures. Explicit instruction involves explanation of rules and giving attention to the "rule-governed nature of L2 structures" (Norris \& Ortega, 2000, p.482). Alternatively, rule explanation is not emphasised in implicit instruction. The meta-analysis by Norris and Ortega (2000) showed a significant difference between the effectiveness of these treatments "treatments involving an explicit focus on the rule-governed nature of L2 structures are more effective than treatments that do not include such a focus" (p. 483).

It is possible to better understand L2 instruction by considering the particular strategies that are taught to students and/or used by students to achieve L2 learning outcomes. Early classifications utilised a dichotomy and distinguished between direct and indirect strategies. This depended on whether a strategy "contributed directly to L2 learning" or was "indirectly involved with language learning" (Hsiao \& Oxford, 2002, p. 370). More recently, polytomous classifications have been developed. For example classifying strategies as: meta-cognitive, cognitive or socio-affective; or in a similar but more detailed way, as meta-cognitive, cognitive, memory, compensation, social, or affective (Hsiao \& Oxford, 2002, p. 371). Meta-cognitive strategies include advance organisers, self-management, functional planning, self-monitoring, and self evaluation; cognitive strategies include repetition, translation, grouping, note-taking, deduction, keyword, contextualisation, transfer, and inferencing; and socio-affective strategies include cooperation, question for clarification, and self-talk (Hsiao \& Oxford, 2002, p. 371).

Other constructs commonly associated with academic motivation and academic success have also been the subject of L2 learning research. For example, self-regulation, selfconcept and self-efficacy (see Mills, Pajares \& Herron, 2007; Vandergrift, Goh, Mareschal \& Tafaghodtari, 2006). These constructs are contextually dependent so care needs to be exercised in their application for explaining L2 learning since "... L2 learning is different from the learning of other subject matters" (Hsiao \& Oxford, 2002, p. 378). For example, when studying the self-efficacy of college Intermediate level French students, Mills, Pajares and Herron (2007, p. 423) operationally defined constructs such as self-concept in terms of the language being learnt - "French learning self-concept".

While constructs such as meta-cognition and cognition can be used to categorise strategies that have respectively similar characteristics, these constructs are more complex 
than simply a conglomeration of strategies. For example, in the case of meta-cognition, Vandergrift, Goh, Mareschal and Tafaghodtari (2006, p. 433) point out that it comprises both assessment of knowledge or ability and also "... orchestrate[ing] different mental processes during problem solving". This conception of meta-cognition has elements of both knowledge and action.

Since instruction involves action, explicit/implicit knowledge is different from explicit/implicit instruction. Having made a distinction between knowledge and instruction, the nature of L2 knowledge is another important aspect of L2 learning. Ellis (2004) differentiated between explicit and implicit knowledge. Explicit knowledge is "knowledge about language and about the uses to which language can be [not is] put" (p. 229). Implicit knowledge can be explained as "basic linguistic competence", the kind of knowledge that underlies everyday language use", and does not involve "meta-linguistic awareness" (Ellis, 2004, p. 232). Ellis (2004, pp. 243 - 244) identified the following examples of explicit L2 knowledge: pronunciation; vocabulary; grammar; pragmatic aspects (e.g. "whether a message contains sufficient information for its comprehension by an addressee"); and socio-critical features (e.g. "to assert one's right to something on the basis of one's class, gender or ethnicity").

Explicit L2 knowledge about socio-critical features of learning is reflected in the socioaffective dimension of L2 instruction. This dimension concerns the management of emotions, feelings and emotional states (affect) and the techniques used when interacting with others (social interaction). This is reflected in formal instructional goals (e.g. curriculum outcomes) which emphasise the cultural relevance of studying a second language. From the perspective of learning processes in contrast to learning outcomes, socio-affective instructional strategies and procedures strongly influence motivation, decision-making and performance (Csizer \& Dornyei, 2005; Masgoret \& Gardner, 2003). For example, Masgoret and Gardner (2003, p. 205) found that “... attitudes towards the learning situation, integrativeness, motivation, integrative orientation, and instrumental orientation, are all positively related to achievement in a second language". Of these five variables, motivation had the strongest relation with L2 achievement. Socio-affective outcomes are a significant component of L2 curricula and in conjunction with associated instructional methods, help characterise L2 teaching and learning.

Notwithstanding motivation being a proven predictor of success in SLA, aptitude for L2 learning is also commonly accepted as a strong predictor in both formal settings and natural circumstances (Ellis, 2004). Ellis (2004, p. 494) viewed aptitude for learning a second language as a "special propensity for learning L2". Kiss and Nikolov (2005, p. 101) elucidated:

"Language learning aptitude has generally been regarded as a cognitively based learner characteristic that is responsible for a considerable portion of the variance in language learning achievement, viewed in terms of the amount of time needed by the individual to learn the material or develop the skill".

Two of the assumptions underlying the notion of 'aptitude' are that it is relatively stable and is either innate or fixed at an early age (Kiss \& Nikolov, 2005). This conception of aptitude reflects some of the nativist theories of SLA. 
In summary, this section of the paper has presented a range of epistemological and methodological perspectives on L2 instruction and learning. It canvassed the nature and types of knowledge that are taught and learnt in SLA with knowledge being differentiated from instruction. The strategies typically applied by teachers and learned by students to enable development of L 2 proficiency were identified. The notion that strategies can be classified in accord with theories of intellectual development and learning was explored (e.g. the study of meta-cognition requires understanding how children monitor and evaluate their learning). The connection between student motivation and L2 performance was examined from an attitudinal perspective. Finally, it was noted that variance in L2 aptitude, in conjunction with variance in motivation, significantly accounts for variation in L2 achievement.

In recent times, the notion of student engagement has been used to describe positive attitudes towards learning and the learning environment. It is proposed that investigating L2 learning in terms of student engagement will provide a view that is conceptually aligned with the theories and methods of L2 learning and instruction. This assertion is examined in the following section.

\section{The notion of student engagement}

The engagement of students can be viewed from several perspectives. For example, from a research perspective, Fredricks, Blumenfeld and Paris (2004) classified the research on engagement three ways:

1. Behavioural - positive conduct, involvement in academic, social or school activities, and in extra-curricular activities;

2. Emotional - positive and negative reactions to teachers, classmates, academics and school; and

3. Cognitive - motivation to comprehend complex ideas and master difficult skills.

From a teacher perspective, the results of phenomenographic investigation conducted by Harris (2008) suggested that teacher conceptions of student engagement could be categorised as follows:

1. "Participating in classroom activities and following school rules" [behaving];

2. "Being interested in and enjoying participation in what happens at school" [Enjoying];

3. "Being motivated and confident in participation in what happens at school" [Being motivated];

4. "Being involved in thinking" [Thinking];

5. "Purposefully learning to reach life goals" [Seeing purpose]; and

6. "Owning and valuing learning" [Owning]" (p. 65).

Significantly, the categorisation by Harris (2008) is similar to the Fredricks, Blumenfeld and Paris (2004) classification. The similarities centre on three constructs: student compliance with classroom and school expectations of conduct/behaviour; positive attitude towards the psycho-social environment; and motivation towards learning. Generally, other conceptions of engagement are consistent with one or more of these three constructs. For example, Glanville and Wildhagen (2007, p. 1021) explained engagement at school as "... a student's behavioural and psychological involvement in the school curriculum”. Hughes and Zhang (2006, p. 406) defined classroom engagement 
to be indicated by “... student effort, attention, persistence, and cooperative participation in learning”. Kenny, Blustein, Haase, Jackson and Perry (2006, p. 272) portrayed school engagement as "... positive attitudes toward school, teachers, classmates, and academic learning”. Janosz, Archambault, Morizot and Pagani (2008, p. 22) saw school engagement as characterising “... both academic (achievement, motivation, involvement in learning activities) and social integration within the school (social isolation/rejection, quality of student-teacher relationships, participation in extracurricular activities)".

Cavanagh, Kennish and Sturgess (2008) proposed a model of student engagement in learning in which engagement at a given time and in a particular context was seen a balance between a student's capability to learn and the expectations of learning. The construct of learning capabilities was operationally defined to comprise two broad attributes of students - the expressive self as typified in studies of self-esteem and selfconcept and the managerial self as typified in studies of self-regulation and self-efficacy (see Martin, 2007). Additionally, resilience was included in the definition due to the prevalence of this notion in the research on school engagement and the conceptual similarity with the other attributes. This construct concerns a student's attitudes towards self and own learning. Alternatively, expectations of student learning was viewed as a student's perceptions of external expectations from the teacher, peers or other influences within the psycho-social learning environment. A framework developed by Wiggins and McTighe (2001) to explain learning for understanding was used to operationally define this construct. Wiggins and McTighe (2001) identified six facets of understanding. These are: can explain; can interpret; can apply; has perspective; can empathise; and has selfknowledge. A framework depicting student's capability to learn and the expectations of learning constructs and the respective sub-constructs is presented in Appendix 1. This also shows indicator statements written to define each sub-construct.

Finally, in advancing the proposition that studying engagement in learning will illuminate learning and instructional aspects of the L2 classroom, it needs to be recognised that this will entail focus on the socio-psychological environment and the processes of learning. The knowledge and skills that need to be learned for proficiency in the second language and also the innate linguistic aptitude of the learner will therefore not be directly considered in this study.

\section{Research objectives}

The aim of the study was to investigate the engagement in learning of secondary school students studying Japanese as a second language. The specific research questions were:

1. How do secondary school students view their engagement in classroom learning of Japanese?

2. How do they perceive their capabilities for classroom learning of Japanese?

3. How do they perceive the expectations placed on their classroom learning of Japanese?

\section{Instrumentation}

The Survey of Engagement in Learning Japanese (see Appendix 2) is a self-report instrument utilising a four-category response scale (strongly agree, agree, disagree, and strongly disagree). It comprises two 25 -item sub-scales. There are 25 items on learning capabilities and 25 items on expectations of learning. Since self-knowledge is more about 'self' than external expectations, this sixth facet was not included as a subconstruct within expectations of learning. There are five items for each of the sub- 
constructs, and these items were written in order of difficulty with the first item in the group expected to be easier to affirm than the subsequent items.

\section{Procedure}

The sample was 279 students from two Perth metropolitan senior high schools.

Participation was voluntary. The characteristic of the sample are presented in Table 1 below.

Table 1.

\begin{tabular}{|c|c|}
\hline \multicolumn{2}{|c|}{ Sample characteristics } \\
\hline Year Eight & 161 \\
\hline Year Nine & 75 \\
\hline Year Ten & 18 \\
\hline Year Eleven & 10 \\
\hline Year twelve & 15 \\
\hline Total & 279 \\
\hline Girls & 152 \\
\hline Boys & 127 \\
\hline Total & 279 \\
\hline
\end{tabular}

Scores from 1 to 4 were entered into the computer package RUMM2020 (Andrich, Sheridan, Lyne \& Luo, 2003) with missing data coded as 9. Data were then analysed using the Rasch Rating Scale Model (Andrich, 1978a \& 1978b) to test the measurement properties of the data. The following six criteria are met when the data fit the Model:

1. The items are measuring a single continuous latent variable - the scale is unidimensional;

2. The item responses are independent of one another - local independence. The only relation between items is explained by the conditional relationship with the latent variable;

3. Specific objectivity - comparison of two items' difficulty parameters are assumed independent of any group of subjects studied, and comparison of two subjects' trait level does not depend on any subset of items being administered;

4. Relation between subject ability and item difficulty (the Rasch Model) - The probability of endorsing an item is a function of the difference between a person's level on the underlying trait and the difficulty of the item;

5. Calibration - both person ability estimates and item difficulty estimates are measured in logits - for example in the case of person affirmativeness in attitude scales, the logarithmic odds of a person affirming certain statements of attitudes; and

6. Intervality - raw scores are tested against the Rasch Model and when the data fit the model, interval person ability estimates and interval item difficulty estimates are produced.

Two analyses were performed. The first was of the complete data-set to identify items that had a good fit to the model. In the second analysis, data from items which did not fit the model well were deleted and the remaining data were re-analysed. More information on the analytic procedures is presented in the following section on the results of the RUMM2020 analyses. 


\section{Results}

\section{The 50-item scale}

Item thresholds were estimated to show the person ability estimate at which there is an equal probability of the persons selecting two adjacent response categories. For a particular item, the probability of selecting response categories should be ordered according to the overall ability of the persons. This is illustrated for Item 17 in Figure 1Category probability curve for Item 17 . Persons with more engagement are located to the right of the horizontal axis and those with less to the left. The vertical axis is the probability of selecting a response category. Curve 0 (strongly disagree) shows the probability of person located 4 logits below the mean is 0.8 and this decreases to zero as person ability increases. For Curve 1 (disagree), the probability increases from 0.2 for a person located 4 logits below the mean to a maximum value of 0.6 for a person located 1.4 logits below the mean, and then decreases for higher person locations. The intersection of Curve 0 and Curve 1, -2.4 logits is the threshold for the strongly disagree and disagree categories. The other two thresholds are respectively -0.34 logits and 2.01 logits. The ranking of the threshold values is ordered in line with increasing student engagement.

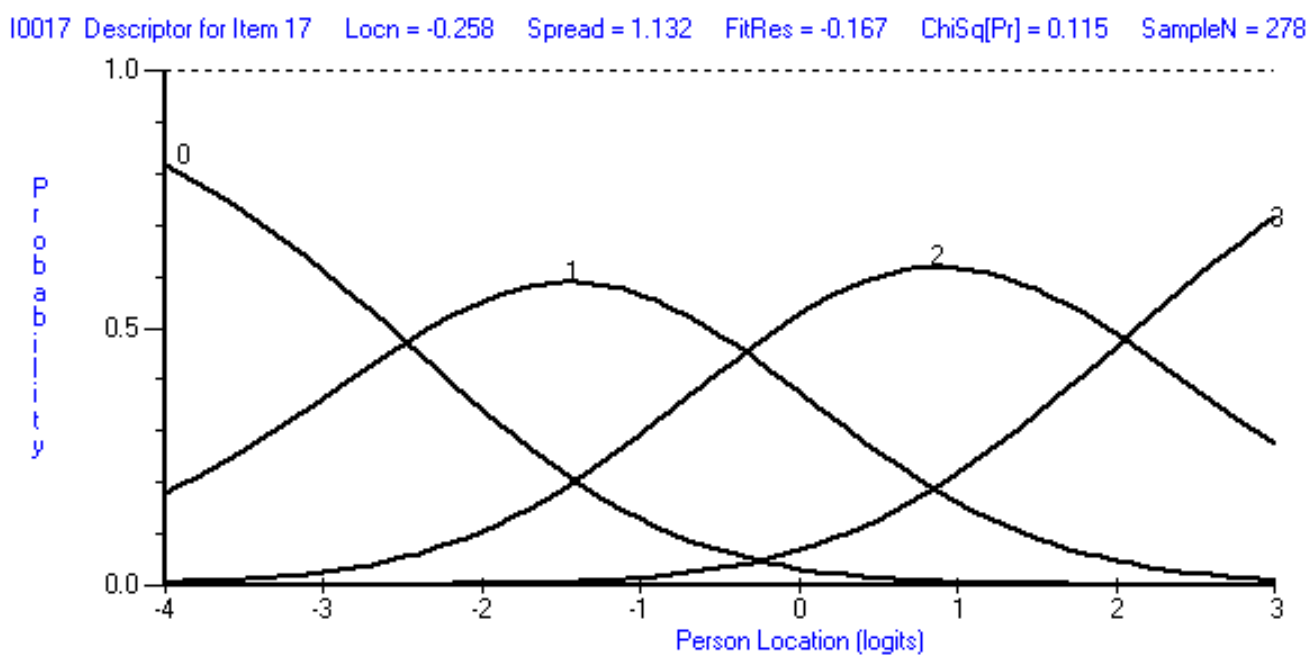

Figure 1. Category probability curve for Item 17

When thresholds were estimated for the 50 item data, Items 2, 12, 21, 22, 36, and 44 had disordering of thresholds. For Item 12, In this class and in this subject I know I can overcome small problems, the respective thresholds were $-0.78,-2.13$, and 2.24 logits as shown in Figure 2 - Category probability curve for Item 12. The first two thresholds are not in order of increasing student engagement mainly due to the selection of the second (Curve 1) and third (Curve 2) response categories. The wording of the item might have confounded students and this could have caused illogical choosing of the categories. Irrespective of the reason for the choice, the data for this item has limited use as a measure of engagement. 


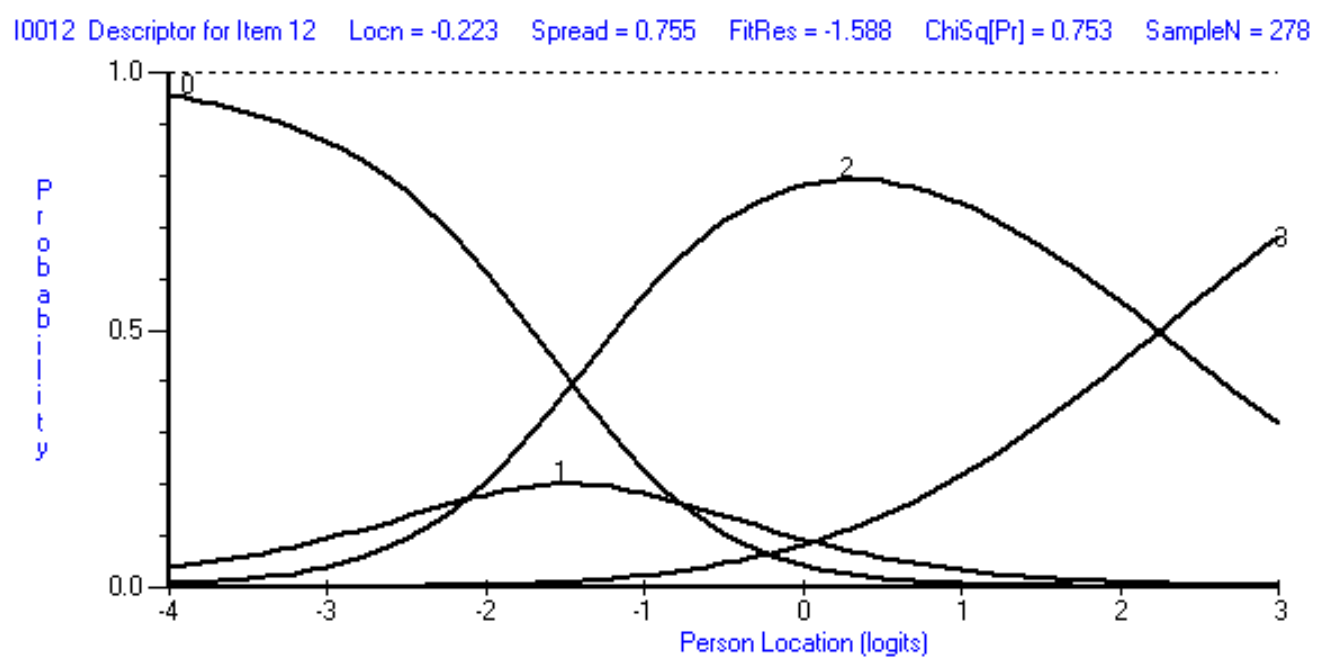

Figure 2. Category probability curve for Item 12

The fit of data to the Model for each of the 50 items was also estimated. When the data fit the model well, the fit residual, the difference between the actual score and that predicted by the Model should be low (RUMM2020 sets a default value of $< \pm 2.5$ ). RUMM2020 also estimates a Chi Square with Bonferroni adjusted probability values indicating data to model fit. Poor data to model fit is illustrated in Figure 3 - Item characteristic curve for Item 5 .

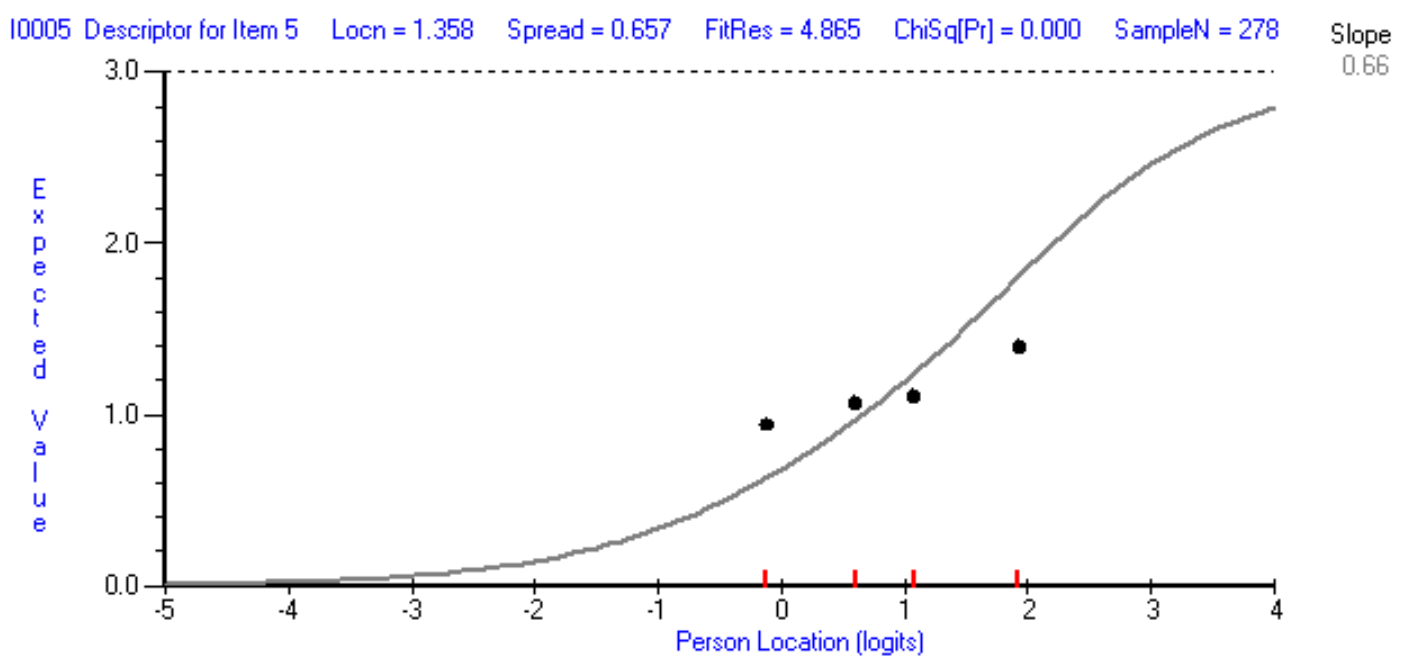

Figure 3. Item characteristic curve for Item 5

The ogive shows the theoretical relation between the expected value and person location for Item 5. The four class interval observed scores do not fit the ogive due to the Class Interval 1 observed score being higher than expected and the Class Interval 4 observed score being lower than expected.

The RUMM analysis revealed eight items had fit residuals greater than \pm 2.5 and/or Chi Square probability values less than the Bonferroni adjusted value. These were Items 3, 59, 24 and 26. 


\section{The 36-item scale}

The RUMM2020 analysis of the remaining data (14 items deleted) showed the data fitted the model well. For example, thresholds were ordered, fit residuals were $< \pm 2.5$, and with the exception of Items 4 and 43, the Chi Square probability values were more than the Bonferroni adjusted value. Additionally, the Person Separation Index (the proportion of transformed scores considered true) was 0.94 indicating high reliability and the ItemTrait Interaction Chi Square probability value was 0.05 suggesting uni-dimensionality. This was confirmed by a Principal Components Factor Analysis of residuals. After the linear Rasch measure was extracted from the data set, there was minimal evidence of common variance in the remaining residuals. A further consideration was the possibility of items functioning differently for certain groups of persons - e.g. girls and boys, different age groups. When differential Item Functioning due to gender and year of schooling was examined by RUMM2020, analysis of variance did not reveal any item bias.

In order to better describe the meaning of the scale and the data, the difficulty the students had in affirming each of the 36 items was estimated in logits. Table 2 contains the items and their difficulties. Lower logits show an item was relatively easy to affirm and higher logits show an item was relatively difficult to affirm. For example, Item 1 (logit -0.23) was easier to affirm than Item 4 (logit 0.14).

Table 2.

Item difficulties

\begin{tabular}{|c|c|c|c|}
\hline \multicolumn{3}{|c|}{ In this class and in this subject } & \multirow{2}{*}{$\begin{array}{c}\text { Logit } \\
-0.23\end{array}$} \\
\hline 1 & SE1 & I am OK & \\
\hline 4 & SE4 & I am confident to make choices and decisions & 0.14 \\
\hline 10 & SC5 & I am one of the best students but still want to improve & 1.52 \\
\hline 11 & $\mathrm{R} 1$ & A little difficulty is OK for me & -0.03 \\
\hline 13 & R3 & I expect to succeed in the end & -0.37 \\
\hline 14 & $\mathrm{R} 4$ & I bounce back after having difficulties & 0.27 \\
\hline 15 & R5 & Anything that goes wrong can be fixed & -0.01 \\
\hline 16 & SR1 & I think about my achievement & 0.00 \\
\hline 17 & SR2 & I am clear about my strengths and weaknesses & -0.20 \\
\hline 18 & SR3 & I know how to learn better & -0.03 \\
\hline 19 & SR4 & I make an effort to improve my learning & 0.09 \\
\hline 20 & SR5 & I am in control of my learning & 0.08 \\
\hline 23 & SEF3 & I can easily identify what will give me difficulty & -0.12 \\
\hline 25 & SEF5 & I never give up & 0.35 \\
\hline \multicolumn{4}{|c|}{ In this class and in this subject, I am expected to } \\
\hline 27 & EXP2 & Explain what I've learnt by using some of my own ideas & 0.15 \\
\hline 28 & EXP3 & Use many of my own ideas to explain what I've learnt & 0.07 \\
\hline 29 & EXP4 & Connect different ideas together & -0.16 \\
\hline 30 & EXP5 & Explain the work differently from how it was taught & 0.69 \\
\hline 31 & INT1 & Repeat what I have been told & -0.46 \\
\hline 32 & INT2 & Show I know the work & -0.75 \\
\hline 33 & INT3 & Explain to other students how the work can be done & 0.17 \\
\hline 34 & INT4 & Compare different ways of understanding the work & 0.29 \\
\hline 35 & INT5 & Have a deep understanding of the work & 0.13 \\
\hline 37 & APP2 & Use what I've learnt previously to help me complete new tasks & -0.93 \\
\hline 38 & APP3 & Use what I've learnt to do things outside of the class & 0.28 \\
\hline 39 & APP4 & Use what I've learnt in many ways outside of the class & 0.69 \\
\hline 40 & APP5 & Find new ways to use what I've learnt outside of the class & 0.46 \\
\hline 41 & PERS1 & Think about what others believe after listening to them & 0.11 \\
\hline 42 & PERS2 & Not ignore opinions different from my own & -0.68 \\
\hline
\end{tabular}


43 PERS3 Understand why others see things the way they do -0.18

45 PERS5 Be very careful about how I react to the views of others -0.37

46 EMP1 Try to understand the views of others -0.49

47 EMP2 Try to be unbiased in understanding the views of others -0.27

48 EMP3 Show how I know others feel differently from me -0.14

49 EMP4 Show sensitivity and concern for the views of others -0.23

50 EMP5 Be willing to change my own views to show respect to others $\quad 0.15$

\section{Discussion}

The Rasch Rating Scale Model is designed for data that are uni-dimensional and measuring a latent trait that is not multi-dimensional. The trait of interest in this study was student perceptions of their engagement in classroom learning of Japanese. In order for the data to fit the model, the two major constructs (learning capabilities and expectations of learning), the ten sub-constructs and the instrument items were all required to indicate the latent trait.

The first salient issue arising from results of the study is the nature of the eight items eliciting data not fitting the model - Items 3, 5-9, 24 and 26. These were:

$\begin{array}{lll}3 & \text { SE3 } & \text { I am proud of what I have achieved; } \\ 5 & \text { SE5 } & \text { There is very little in me that needs to improve; } \\ 6 & \text { SC1 } & \text { I check how well I'm doing by looking at what others do; } \\ 7 & \text { SC2 } & \text { How I feel about myself comes from looking at others; } \\ 8 & \text { SC3 } & \text { I compare myself with others when I need to; } \\ 9 & \text { SC4 } & \text { Comparing myself to others changes what I do; } \\ 24 & \text { SEF4 } & \text { Even when problems are big, I feel I must succeed; and } \\ 26 & \text { EXP1 } & \text { Use the words of others when explaining things. }\end{array}$

The majority of these items elicited data on the students' view of themselves, particularly self-concept. The misfit as illustrated in the item characteristic curves (e.g. Figure Three) shows the observed values for the class intervals are similar and do not vary as the person engagement locations change. From a measurement perspective, the items might not be sufficiently sensitive to aspects of these attributes leading to the level of the attribute not varying with engagement. Theoretically, it is possible that the sub-constructs of selfesteem and self-concept are not indicators of classroom engagement in learning Japanese as theorised. This is notwithstanding socio-affective strategies being recognised in the literature on the learning strategies taught to second language students (Hsiao \& Oxford, 2002). Similarly, the effect of 'context' (e.g. the particular language being learned) on academic motivation constructs (Hsiao \& Oxford, 2002) could explain why self-esteem and self-concept were not found to characterise engagement in the classrooms examined (see Mills, Pajares \& Herron, 2007).

Data on resilience, self-regulation and to a more limited extent self-efficacy, did fit the model well. Self-regulation and self-efficacy are referred to as meta-cognitive strategies in the literature on L2 learning strategies and attainment of learning outcomes (Hsiao \& Oxford, 2002; Vandergrift, Goh, Mareschal \& Tafaghodtari, 2006).

The second salient issue emerging from the results are the trends in the item difficulties presented in Table 2. First, in general, the levels and distributions of the learning capabilities item difficulties and the expectations of learning item difficulties were similar. This suggests a balance between the students' capabilities and what is expected 
of their learning. This balance is consistent with the theory of engagement informing the investigation (see Cavanagh, Kennish \& Sturgess, 2008).

Second, across the learning capabilities sub-constructs there is little variation in the item difficulties with many of the difficulties being within 0.5 logits of the zero point. The majority of the fitting items concern what Martin (2007) described as the 'managerialself' conception of selfhoods that is found in studies of self-regulation and self-efficacy. The similarity in item difficulties could also be due to a lack of variation in these attributes in Japanese L2 students.

Third, in contrast, there are larger differences within the expectations of learning item difficulties. The explanation, interpretation and application items were generally more difficult to affirm than the perspective and empathy items. Thus it might be concluded that expectations of explaining, interpreting and applying were not as characteristic of the Japanese L2 learning environments investigated as were expectations of perspective and empathy.

Fourth, the cognitive strategies of repetition, translation, grouping, note-taking, deduction, keyword, contextualisation, transfer and inferencing (see Hsiao \& Oxford, 2002), are conceptually similar to the explanation, interpretation and application facets of learning for understanding. However the expectations as operationally defined by the instrument items are likely more demanding of students than the L2 learning cognitive strategies. Since explanation, interpretation and application are identified as requisites for deep learning (Wiggins \& McTighe, 2001), perhaps more attention should be given to the higher levels of these facets when cognitive strategies are used in secondary school Japanese L2 learning.

Fifth, the perspective and empathy sub-constructs are conceptually similar to the socioaffective dimension of L2 instruction comprising management of emotions, feelings and emotional states in social interaction. These are associated with L2 curriculum outcomes about cultural relevance, respect and sensitivity; and also motivation, decision-making and performance (Csizer \& Dornyei, 2005). The majority of the item difficulty logits for the perspective and empathy items were relatively low due to students easily affirming these qualities were expected of them in their Japanese L2 classroom. This suggests there was an emphasis on socio-affective outcomes and learning strategies in the classrooms investigated.

\section{Conclusion}

Analysis of data from the Survey of Engagement in Learning Japanese measured constructs found in the extant literature on second language instruction and learning. The students affirmed their resilience, self-regulation and self-efficacy as learners of Japanese and also that this learning required them to explain, interpret, apply, have perspective and have empathy.

The misfitting of data from self-esteem and self-concept items does not necessarily negate these attributes being characteristic of Japanese L2 learners. Rather than modifying the theory of engagement by removing these sub-constructs, more information should be collected on the performance of the items with a view to item re-writing. 
Since the data fitted the Rasch rating Scale Model, the instrument and constituent items should be invariant when administered to other groups of Japanese L2 learners. However, increasing the sample might enable improvement of the metric through consideration of richer data.

Finally, the nationally recognised importance of studying languages other than English, requires better understanding of the instructional, learning and indeed engagement processes in the second language classroom. The construction and testing of appropriate measures is a key way to learn more about second language acquisition.

\section{References}

Andrich, D., Sheridan, B., Lyne, A., \& Luo, G. (2003). RUMM: A windows-based item analysis program employing Rasch unidimensional measurement models. Perth: Murdoch University.

Andrich, D. (1978a). Application of a psychometric rating model to ordered categories which are scored with successive integers. Applied Psychological Measurement, 2(4), 581-594.

Andrich, D. (1978b). Rating formulation for ordered response categories. Psychometrika, 43(4), 561-573.

Bond, T.G. \& Fox, C.M. (2001). Applying the Rasch model: Fundamental measurement in the human sciences. Mahwah, N. J.: Lawrence Erlbaum Associates, Publishers.

Cavanagh, R.F., Kennish, P., \& Sturgess, K. (2008). Development of theoretical frameworks to inform measurement of secondary school student engagement with learning. Paper presented at the 2008 Annual Conference of the Australian Association for Research in Education, Brisbane, November 30-December 4.

Chamot, A. U., \& El-Dinary, P. B. (1999). Children's learning strategies in immersion classrooms. The Modern Language Journal, 83(3), 319-338.

Csizer, K., \& Z. Dornyei. (2005). Language learners' motivational profiles and their motivated learning behaviour. Language Learning 55, 613-59.

Curriculum Council. (2008). 2007 Secondary education statistics (Years 10, 11 and 12). Osborne Park, Western Australia: Curriculum Council.

DEEWR. (2002). Review of the Australian government languages other than English programme (LOTE). Canberra, ACT: Department of Education, Employment and Workplace Relations.

DEEWR. (2008). National Asian Languages and Studies in Schools Program (NALSSP). Canberra, ACT: Department of Education, Employment and Workplace Relations.

Department of Education, Training and the Arts. (2006). Curriculum: Learning, teaching and assessment. City East, Brisbane: The State of Queensland. Retrieved July 10, 2008 from http://education.qld.gov.au/curriculum/area/lote/index.html

Ellis, R. (2004). The study of second language acquisition. Oxford, England: Oxford University Press.

Fredricks, J.A., Blumenfeld, P.C., \& Paris, A.H. (2004). Review of Educational Research, 74(1), 51-109.

Glanville, J.L., \& Wildhagen, T. (2007). The measurement of school engagement: Assessing dimensionality and measurement invariance across race and ethnicity. Educational and Psychological Measurement, 67(6), 1019-1041.

Harris, L.R. (2008). A phenomenographic investigation of teacher conceptions of student engagement. The Australian Educational Researcher, 35(1), 57-79.

Himizu, H., \& Green, K. (2007). Japanese Language Educators' Strategies for and Attitudes toward Teaching Kanji. Language Learning, (57)1, 57-85.

Hsiao, T. Y., \& Oxford, R. L. (2002). Comparing theories of language learning strategies: A confirmatory factor analysis. Modern Language Journal, 86(3), 368-383. 
Hughes. J.N., \& Duan Zhang, D. (2006). Effects of the structure of classmates' perceptions of peers' academic abilities on children's perceived cognitive competence, peer acceptance, and engagement. Contemporary Educational Psychology, 32, 400-419.

Janosz, M., Archambault, I., Morizot, J., \& Pagani, L.S. (2008). School engagement trajectories and their differential predictive relations to dropout. Journal of Social Issues, 64(1), 21-40.

Kenny, M.E., Blustein, D.L, Haase, R., Jackson, J., \& Perry, J.C. (2006). Setting the stage: Career development and the student engagement process. Journal of Counselling Psychology, 53(2), 272-279.

Kiss, C. \& Nikolov, M. (2005). Developing, piloting, and validating an instrument to measure young learners' aptitude. Language Learning 55, 99-150.

Larsen-Freeman, D. (2007). Reflecting on the Cognitive-Social Debate in Second Language Acquisition. Modern Language Journal, (91)5, 773-787.

Lo Bianco, J. (2000). After the Tsunami, some dilemmas: Japanese language studies in multicultural Australia. Melbourne, Victoria: Language Australia.

Macaro, E. 2006. 'Strategies for language learning and for language use: Revising the theoretical framework,' The Modern Language Journal, 90, 320-37.

Masgoret, A.M., \& Gardner, R.C. (2002). Attitudes, motivation, and second language learning: A meta-analysis of studies conducted by Gardner and Associates. Language Learning, 53(1), 123-164.

Martin, J. (2007). The selves of educational psychology: Conceptions, contexts, and critical considerations. Educational Psychologist, 42(2), 79-89.

Mills, N., Pajares, F., \& Herron, C. (2007). Self-efficacy of college intermediate French students: Relation to achievement and motivation. Language Learning 57(3), 417-422.

Ministerial Council on Education, Employment, Training and Youth Affairs. (1999). The Adelaide Declaration on National Goals for Schooling in the Twenty-first Century. Carlton, South Victoria, Australia: MCEETYA.

Mori, Y. (1999). Beliefs about language learning and their relationship to the ability to integrate information from word parts and context in interpreting novel kanji words. The Modern Language Journal, 83, 534-547.

Mullock, B. (2006). The pedagogical knowledge base of four TESOL teachers. The Modern Language Journal, 90, 48-66.

Hayato Nakagama, H., \& Tanaka, S. (2004). A connectionist model for variable binding, case role assignment and inference in language processing. International Congress Series (Elsevier), 1269, 141-144.

Norris, J. M., \& Ortega, L. (2000). Effectiveness of L2 instruction: A research synthesis andquantitative meta-analysis. Language Learning, 50, 417-528.

Shimizu, H., \& Green, K. (2002). Japanese language educators' strategies for and attitudes towards teaching kanji. The Modern Language Journal, 86, 227-241.

Tang, Y. (2006). Beyond behaviour: Goals of cultural learning in the second language classroom. Modern Language Journal,(90)1, 86-99.

Vandergrift, L., Goh, C., Mareschal, C. \& Tafaghodatari, M.H. (2006). The Metacognitive Awareness Listening Questionnaire (MALQ): Development and validation. Language Learning, 56, 431-462.

Vygotsky, L.S. (1978). Mind and society: The development of higher psychological processes. Cambridge, MA: Harvard University Press.

Vibert, A., \& Shields, C. (2003). Approaches to student engagement: Does ideology matter? McGill Journal of Education, 38(2), 221-240.

Wiggins, G, \& McTighe, J. (2001). Understanding by design: A brief introduction. New Jersey: Prentice Hall Inc. 


\section{Appendix 1: Theoretical Framework}

Leaning capabilities

\begin{tabular}{|c|c|c|c|c|c|}
\hline 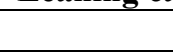 & Self-esteem & Self-concept & Resilience & Self-regulation & Self-efficacy \\
\hline \multirow[t]{4}{*}{$\begin{array}{l}\text { More } \\
\text { capability }\end{array}$} & $\begin{array}{l}\text { Has positive } \\
\text { self image }\end{array}$ & $\begin{array}{l}\text { Strives to be } \\
\text { perfect }\end{array}$ & $\begin{array}{l}\text { Unqualified } \\
\text { expectations } \\
\text { of coping }\end{array}$ & $\begin{array}{l}\text { Responsible for } \\
\text { learning }\end{array}$ & $\begin{array}{l}\text { Perseveres in } \\
\text { the face of } \\
\text { adversity }\end{array}$ \\
\hline & $\begin{array}{l}\text { Confident to } \\
\text { make } \\
\text { decisions }\end{array}$ & $\begin{array}{l}\text { Motivated by } \\
\text { self reflection }\end{array}$ & $\begin{array}{l}\text { Can deal with } \\
\text { failure }\end{array}$ & $\begin{array}{l}\text { Improves own } \\
\text { learning }\end{array}$ & $\begin{array}{l}\text { Has } \\
\text { determination }\end{array}$ \\
\hline & $\begin{array}{l}\text { Has pride in } \\
\text { self }\end{array}$ & Self reflecting & $\begin{array}{l}\text { Expects } \\
\text { success }\end{array}$ & $\begin{array}{l}\text { Understands } \\
\text { own learning }\end{array}$ & $\begin{array}{l}\text { Recognises } \\
\text { contextual } \\
\text { influences }\end{array}$ \\
\hline & $\begin{array}{l}\text { Trusts self to } \\
\text { act }\end{array}$ & $\begin{array}{l}\text { At ease } \\
\text { comparing self } \\
\text { with others }\end{array}$ & $\begin{array}{l}\text { Overcomes } \\
\text { small setbacks }\end{array}$ & $\begin{array}{l}\text { Assesses own } \\
\text { learning }\end{array}$ & $\begin{array}{l}\text { Has } \\
\text { expectations } \\
\text { of self }\end{array}$ \\
\hline $\begin{array}{l}\text { Less } \\
\text { capability }\end{array}$ & $\begin{array}{l}\text { Sees worth in } \\
\text { self }\end{array}$ & $\begin{array}{l}\text { Compares self } \\
\text { with others }\end{array}$ & $\begin{array}{l}\text { Is aware of } \\
\text { problems }\end{array}$ & $\begin{array}{l}\text { Aware of } \\
\text { learning }\end{array}$ & Makes effort \\
\hline
\end{tabular}

Expectations of learning for understanding

\begin{tabular}{|l|l|l|l|l|l|}
\hline & Explanation & Interpretation & Application & \multicolumn{1}{|c|}{ Perspective } & \multicolumn{1}{|c|}{ Empathy } \\
\hline $\begin{array}{l}\text { More } \\
\text { demanding }\end{array}$ & Sophisticated & Profound & Masterful & Insightful & Mature \\
\hline & In-depth & Revealing & Skilled & Thorough & Sensitive \\
\hline & Developed & Perceptive & Able & Considered & Aware \\
\hline $\begin{array}{l}\text { Less } \\
\text { demanding }\end{array}$ & Naive & Interpreted & Apprentice & Aware & Developing \\
\hline
\end{tabular}




\section{Appendix 2: Survey of Engagement in Learning Japanese}

Year

Gender (male or female)

\section{INSTRUCTIONS}

If you strongly agree with the statement, please tick 4

If you agree with the statement, please tick 3

If you disagree with the statement, please tick 2

If you strongly disagree with the statement, please tick 1

$\begin{array}{llll}1 & 2 & 3 & 4 \\ 1 & 2 & 3 & 4 \\ 1 & 2 & 3 & 4 \\ 1 & 2 & 3 & 4\end{array}$

\section{PART A: How I see myself in this class}

\section{In this class and in this subject}

$\begin{array}{ll}\text { SE1 } & \text { I am OK } \\ \text { SE2 } & \text { I feel good in myself } \\ \text { SE3 } & \text { I am proud of what I have achieved } \\ \text { SE4 } & \text { I am confident to make choices and decisions } \\ \text { SE5 } & \text { There is very little in me that needs to improve } \\ \text { In this class and in this subject }\end{array}$

SC1 I check how well I'm doing by looking at what others do

SC2 How I feel about myself comes from looking at others

SC3 I compare myself with others when I need to

SC4 Comparing myself to others changes what I do

SC5 I am one of the best students but still want to improve

In this class and in this subject

R1 A little difficulty is OK for me

R2 I know I can overcome small problems

R3 I expect to succeed in the end

R4 I bounce back after having difficulties

R5 Anything that goes wrong can be fixed

In this class and in this subject

SR1 I think about my achievement

SR2 I am clear about my strengths and weaknesses

SR3 I know how to learn better

SR4 I make an effort to improve my learning

SR5 I am in control of my learning

In this class and in this subject

SEF1 I try when I need to

SEF2 I want to be successful

SEF3 I can easily identify what will give me difficulty

SEF4 Even when problems are big, I feel I must succeed

SEF5 I never give up

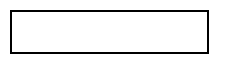


In this class and in this subject, I am expected to

EX1 Use the words of others when explaining things

EX2 Explain what I've learnt by using some of my own ideas

EX3 Use many of my own ideas to explain what I've learnt

EX4 Connect different ideas together

EX5 Explain the work differently from how it was taught

In this class and in this subject, I am expected to

INT1 Repeat what I have been told

INT2 Show I know the work

INT3 Explain to other students how the work can be done

INT4 Compare different ways of understanding the work

INT5 Have a deep understanding of the work

In this class and in this subject, I am expected to

AP1 Follow instructions to complete tasks

AP2 Use what I've learnt previously to help me complete new tasks

AP3 Use what I've learnt to do things outside of the class

AP4 Use what I've learnt in many ways outside of the class

AP5 Find new ways to use what I've learnt outside of the class

\section{In this class and in this subject, I am expected to}

PS1 Think about what others believe after listening to them

PS2 Not ignore opinions different from my own

PS3 Understand why others see things the way they do

PS4 Be fair in making judgements about how others see things

PS5 Be very careful about how I react to the views of others

In this class and in this subject, I am expected to

EM1 Try to understand the views of others

EM2 Try to be unbiased in understanding the views of others

EM3 Show how I know others feel differently from me

EM4 Show sensitivity and concern for the views of others

EM5 Be wiling to change my own views to show respect to others
Strongly

Disagree

$\begin{array}{ccc}\text { Disagree } & \text { Agree } & \begin{array}{c}\text { Strongly } \\ \text { Agree }\end{array} \\ 2 & 3 & 4 \\ 2 & 3 & 4 \\ 2 & 3 & 4 \\ 2 & 3 & 4 \\ 2 & 3 & 4\end{array}$

\begin{tabular}{c|ccc}
$\begin{array}{c}\text { Strongly } \\
\text { Disagree }\end{array}$ & Disagree & Agree & $\begin{array}{c}\text { Strongly } \\
\text { Agree }\end{array}$ \\
1 & 2 & 3 & 4 \\
1 & 2 & 3 & 4 \\
1 & 2 & 3 & 4 \\
1 & 2 & 3 & 4 \\
1 & 2 & 3 & 4
\end{tabular}

\begin{tabular}{c|ccc}
$\begin{array}{c}\text { Strongly } \\
\text { Disagree } \\
1\end{array}$ & Disagree & Agree & $\begin{array}{c}\text { Strongly } \\
\text { Agree }\end{array}$ \\
1 & 2 & 3 & 4 \\
1 & 2 & 3 & 4 \\
1 & 2 & 3 & 4 \\
1 & 2 & 3 & 4 \\
1 & 2 & 3 & 4 \\
\end{tabular}

\begin{tabular}{c|ccc}
$\begin{array}{c}\text { Strongly } \\
\text { Disagree } \\
1\end{array}$ & Disagree & Agree & $\begin{array}{c}\text { Strongly } \\
\text { Agree }\end{array}$ \\
& 2 & 3 & 4 \\
1 & 2 & 3 & 4 \\
1 & 2 & 3 & 4 \\
1 & 2 & 3 & 4 \\
1 & 2 & 3 & 4 \\
\end{tabular}

\begin{tabular}{|c|c|c|c|}
\hline $\begin{array}{l}\text { Strongly } \\
\text { Disagree }\end{array}$ & Disagree & Agree & $\begin{array}{c}\text { Strongly } \\
\text { Agree }\end{array}$ \\
\hline 1 & 2 & 3 & 4 \\
\hline 1 & 2 & 3 & 4 \\
\hline 1 & 2 & 3 & 4 \\
\hline 1 & 2 & 3 & 4 \\
\hline 1 & 2 & 3 & 4 \\
\hline
\end{tabular}

THANK YOU VERY MUCH FOR TAKING THE TIME TO COMPLETE THIS SURVEY 
